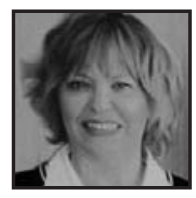

\title{
On Screen: Writing, Images and What It Means to Be a Reader
}

\author{
Abigail Anderson, Quebec Ministry of Education
}

\section{ABSTRACT}

The majority of English Language Arts curricula in North America, if not worldwide, draw on traditional literary texts as their core content. By contrast, the confluence of image and written word on contemporary texts-including the literary-and the impact this evolution has on our comprehension of the changing face of literacy is one of the most compelling issues in contemporary pedagogy. It seems clear that the rise of the new media and its range of textual genres challenge prevailing views about what it means to be a reader and how reading is taught in our schools. Since word and image demand different reading paths and strategies, how can teachers begin to re-vision their pedagogical practices while taking an active role in addressing the literacy needs of their elementary and secondary students?

\section{A World of Texts}

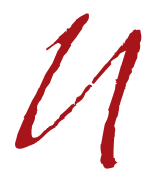

nlike writing, we come to images like those on television and the Internet with the understanding that we are reading them-that we do not need to learn the kinds of codes and conventions that are basic when learning to read the written word or ask the kinds of questions we learn to use when interpreting a written text. Too, when we come to the screen, to a communication environment that integrates images, sound and speech, the assumption is that once we learn how it works technically, the rest follows in a kind of natural, logical way.

In our work with teachers around the province of Quebec over the last five years, it became quickly apparent that learning to read both images and multimodal texts that incorporate images and print in formal, explicit ways is often regarded as a 
"frill" in an otherwise sound English Language Arts (ELA) program. The misperception that we come to these texts with a kind of "built-in wiring" to comprehend and evaluate them, making formal instruction virtually unnecessary, is a prevailing notion in contemporary elementary, secondary and post-secondary education, including teacher education programs. In ELA classrooms it is the literary text that forms the nucleus of literacy pedagogy, a tradition based on the privileged place of the texts of "high culture" in the evolution of the discipline over the last century. Moreover, current examining trends continue to reinforce the connection between literary analysis and the attainment of literacy. Understandable, then, are the deep reservations teachers harbor about the texts of popular, or "low" culture and their conviction that bringing the new media into the classroom will diminish the status of the literary text, as well as lower the standards by which the educational system has historically determined literacy and academic excellence in the discipline. Of course there are other issues deeply related to these convictions, including the complexity of weaving aspects of student culture and sensibility into contemporary teaching practice. However, it is doubtful that the world will wait for the culture and content of schooling to catch up, leaving our students the unenviable task of spanning a breach which could have disastrous consequences for their future in contemporary society. In this light, whether we teach prospective teachers, graduate students, teachers in the field, children or youth in our schools, it is time to re-vision what it means to be a reader in a world of rapidly evolving communication technologies and communication genres. At the heart of our inquiry needs to be another tradition of equal importance to our profession: namely, the social contract of preparing students for life in a democratic society by teaching them critical reasoning skills that will enable them to judge the significance of what they read, see and hear for themselves. It is, after all, this capacity to interact with the world in a conscious, critical fashion that is deeply associated with our understanding of freedom, power and concepts of self and other.

\section{Reading print and image}

The texts we read on television, the Internet or in a newspaper-even when in real time where we feel that we are there "as it happens"-are constructed. As is true of any written text, from fairy tale to Shakespearean tragedy, the texts we view are never neutral in their meanings, messages and intent. They are deliberate constructs that carry stylized and structured meanings and messages to a predetermined readership. Here the comparisons between image and print end, since the world shown in images is different from the world told in a written text. The systems of representation used to create each world offer different possibilities, resulting in distinctive ways of representing and constructing meaning. ${ }^{1}$ And although images may 
appear to be more accessible than print, the meanings they connote and the intent of those who produce them are no less complex. Standards of success and beauty, the outcome of national and local elections, perspectives on world events and issues, the evolution of the concept of community and the rise of a consumer mega-culture comprise a modest list of just some of the aspects of contemporary life that are mediated by powerful images constructed to position their readers.

Indicative of the prevalence of new media in shaping our actions, attitudes and experiences is the relatively recent coverage of the death of Michael Jackson. In the real time of the event, the mass media ran through a cycle of narratives, from the arrival of the ambulance transporting the superstar to hospital, through the announcement of his death and the worldwide response of his fans, to the denouement, in the form of a televised and streamed memorial service for the "King of Pop." Coverage of the event, circumscribed by the recurring mantra that Jackson was a person "... we all knew and loved," dominated channels of communication for ten days.

This kind of relentless coverage of death and disaster is a familiar venue to most of us by now. As Henry Giroux (1988) was first to observe, a particularly powerful aspect of screen media, beginning with television, is their ability to construct us into a virtual community in a matter of minutes. Giroux goes on to point out that there is a connection between the debut of television and the need of those in power to give their citizenry, who had emerged from the Second World War as active participants in democratic life, a real sense that they could continue to participate in decisions made by leaders on their behalf. Television provided a perfect environment, since it could convey a sense of real time and, therefore, a genuine connection between what readers saw on their televised news programs in the 1950s and their sense of social involvement in what was going on in their country and in the world. Today, the fact that our understanding of the world and of events that take place in it is mediated by television, radio and the Internet is something we tend to take for granted.

However, as would be the case with regard to any event we read "on screen," the television and Internet narrative of Jackson's life and times involved the scripting, cutting and editing of appropriate images to convey a meaning and/or message, interviews and information designed to achieve a specific effect, decisions about content based on a target audience and optimal viewing times, and the use of sound, music, color and an overriding organizational device, such as a stance or a viewpoint. In the days immediately following Jackson's death, it also became clear just how vulnerable images are to processes of de-contextualization, which is what makes them 
so versatile, on the one hand and so easy to manipulate, on the other. Images can be plucked from the landscape — the foreground and background-in which they were originally rendered with the simple flick of a switch, making their potential as sources of meaning and the so-called truths they convey virtually infinite. While literate people are familiar with the journalistic style of pulling quotations and factual material from their original context to build an argument, the possibilities afforded by the combination of screen, speech and visual discourse enable producers to connote messages and meanings rapidly and, apparently, succinctly. Indeed, images are powerful tools when enlisted as consensus-creating tools. Portraits of Michael Jackson alternated between the construct of an unstable and tormented genius in the form of "Jacko," to the proverbial child-star who, like Peter Pan, could never grow up and built a "Wonderland" to buffer his own innocence from the encroachment of the adult world, to the musical genius of albums such as Thriller (Jackson, 1982). In several instances, the same image or footage was used to connote quite different meanings, as the narrative moved away in time from its coverage of the events surrounding Jackson's death to reflections about his contribution to the popular music entertainment industry.

The terms of reader-text engagement when images are central to our understanding involves the comprehension that the meaning or message we construct is designed by the relationship between the elements of the composed image(s), print or speech (i.e., in multimodal texts), the intent of the producer and the social context in which the text is situated. Since the texts of television and the Internet are fleeting in comparison to the written texts of book, magazine or newspaper, readers process intended meanings at rapid speed without necessarily subjecting them to the kind of critical questioning they are likely to bring to texts that they can reread and reconsider. The rapid-fire processing of the texts of the new media, given their power to influence our values, beliefs and view of the world, needs to be examined in our classrooms, in order that the young can begin to consider how texts are designed to influence them in quite explicit ways. One way to begin the process is by examining one of the oldest forms of image production, the photograph.

\section{Visual design}

Despite our sense that still or moving images allow us complete liberty in the meanings we assign to them, images demand a very particular kind of reading. When we look at the photograph below, for example, certain elements are very precise and their interrelationship connotes, in turn, meaning. For example, the woman is dressed in a manner that tells us this is not a recent photo. Her hat, in particular, 
suggests the Flapper era of the 1920s. In the background is a building of odd proportions and its canvas-type roofing suggests a seasonal structure. We also notice that the photograph is posed-rider and horse are attending to the camera. The positioning of the subjects tell us that the portrait was meant to capture a special moment or perhaps to hold a memory in place, since, in the tradition of portrait photography, the foregrounding of the subjects is a convention that connotes their significance. The photographer is likely a professional—or, if not, a gifted amateur-given the grace of the composition, the textures of grass, leather, skin and so forth, and the play of light. In present time, all of the elements in the composition combine to evoke a sense of nostalgia for a past that is no longer.

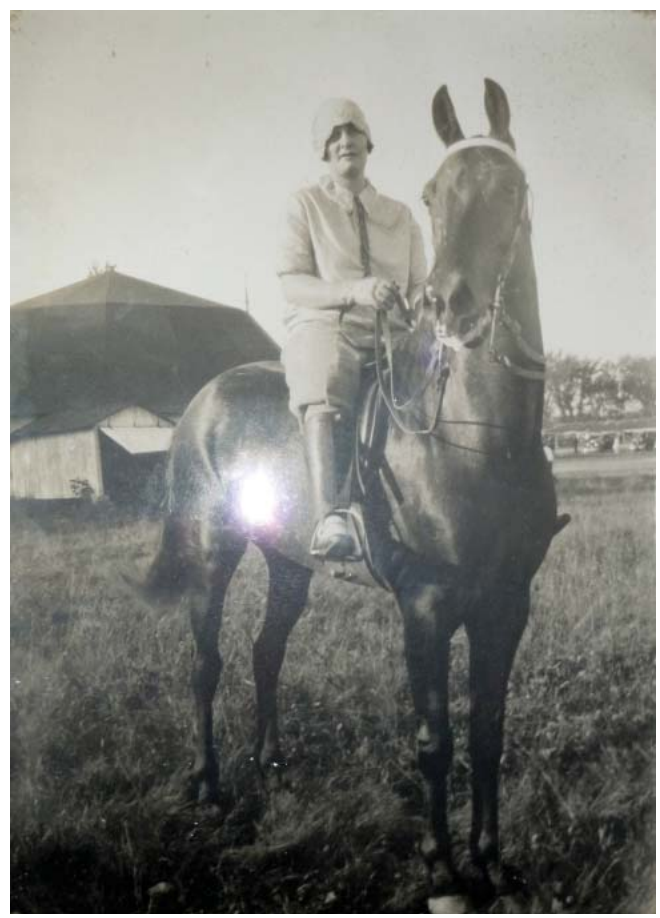

Fig. 1: Photograph of rider on horse

Images are semantically precise and clear, and the meaning(s) we associate with them depend upon the relationship between the elements in the representation (Kress, 2003) and how we interpret them, aligning the context in which the image appears, its visual elements and our own social context for reading as we build meaning. In other words, the reading path of an image asks readers to explore the relationship and relevance of its visual elements to the context(s) in which they are situated, 
and from which their meaning derives. The world depicted in images is a designed world and this is precisely why it can hold memories in place for us over time. As example, the photo in question will always be one of my most treasured family heirlooms. It portrays my grandfather's champion mare outside the fairgrounds in Huntingdon, Quebec, a scene of her many victories. Since my grandfather was also a resident of Huntingdon, his beautiful black mare became a local character and accrued her own fan club-when she entered the Huntingdon arena, the audience stood to applaud her. My grandfather and his beautiful mare shared a narrative that held a very central place in his life. She had been an abused, angry filly when he bought her and through his patience and perseverance, she grew to trust and love him. My grandfather had been a very sickly child and a rather frail young man, making it impossible for him to follow in the farming tradition of his father. There was something in the relationship between the tiny man and his tall, black mare that overcame the pain and disappointment of his youth. Her portrait hung over his desk until the day he died. Each time I look at this photograph, I am plunged into memories of weekends spent with my grandparents when I was a little girl and the shared narratives that held us close.

The casual viewer, however, shares none of this personal context, reminding us that an image-based representation, such as the photograph above, also withholds information. It is not only the wider social context of my family history that the photograph eludes. Even I am unable to read beyond what the image shows me-I have no idea if my grandfather was standing next to the photographer in order to get the mare's attention, or what else was beyond the periphery of the lens. Cameras "lie"the person capturing the image or images is at a particular place in a much larger and possibly more complex landscape that he or she has, consciously in this case, relegated to the periphery of the lens. Whether a personal photograph or televised footage, we are shown only a slice of the whole, actual event and it is this edited representation that constitutes the description of a world in a designed, deliberate fashion.

In writing, even when the genre of a text is unfamiliar to its reader, the combination of textual structures, linguistic structures such as syntax and lexical elements, as well as the codes and conventions of the genre establish a reading path that cues readers to build an interpretation. Readers bring their literacy repertoirestheir experience with a given genre, with reading written texts and their own personal knowledge and experience-to the task. As reading experience grows, readers' interpretations become more fluent. The possibilities inherent in writing are responsible for giving us the impression that the written text offers a kind of depth of 
meaning that is not available through the lens of a camera or on the screens of television or other new media. It may well be this impression that is responsible for the skepticism of many educators regarding the intrusion of popular media such as television and the Internet on the traditional texts that have always formed the core of their curriculum. However, the impression that writing offers more to readers than other types of texts is flawed, if only because the practice of interpreting the written text is more established than that of teaching readers how meaning is designed in contemporary visual media. Literacy in the twenty-first century is based on the prerequisite of knowledge about both the demands and the possibilities inherent in two distinct systems of representation and three modes of discourse-written, visual and spoken. Rather than questioning which system offers or withholds more, it becomes critical to better comprehend the possibilities inherent in each.

\section{Turning to a new page: image and print in the classroom}

Writing provides us with a semantic and semiotic openness on which to base interpretation, largely due to the manner in which its fixed reading path, stable syntax and pre-established lexical elements combine as a system for communicating meaning. By contrast, texts that are composed of images, illustrations and a range of visual effects convey meaning(s)/message(s) based on the design, or relationship, among their visual and discursive elements. And, since familiar contemporary texts increasingly blend image or illustration with either writing or speech, it is impossible to render a critical interpretation of them using what we have learned about reading and writing print. In other words, readers need to learn interpretive reading strategies based on the relevance of elements in a given text that incorporates image(s) and writing and/or speech. The context of this kind of reading demands knowledge of different modes of discourse, together with an awareness of the text's intended audience and a capacity to weave these aspects together when reading the text. Thus, readers need to bring an understanding of the production process itself to their reading, in order to move from literal to interpretive reasoning about the significance of the message/meaning in a text. As an example, when readers understand that television is funded by commercials that are shown at optimum times given the target audience of a particular program, they are able to weave this knowledge into their explanation of why it is that Saturday morning cartoons are accompanied by toy and fast-food commercials, whereas weekday afternoon soap operas are accompanied by promotions of household products. Moreover, readers can begin to draw on specific aspects of how the commercial appeals to its audience to frame their own interpretations. Over time, secondary students learn to consider the interface between the advertising and television industries, in order to look critically at prime- 
time programming. All of these examples draw on the notion that establishing relevance when reading the texts of visual discourse is the key to becoming a critical reader.

Media educators have long stressed the difference between teaching about the media and teaching through the media. The well-established practice of building reading-writing connections in the case of written texts is founded on a similar principle: namely, that we learn how writing works by adopting the roles of both readers and writers of texts. Similarly, learning about the image demands that students be given the opportunity to both read and produce them. When students produce multimodal texts (i.e., texts that incorporate images and/or writing and/or speech), they gain the opportunity to enter fully into different systems of representation in a manner that deepens their understanding of audience, context and the principles of relevance that govern multimodal meanings and messages.

Even the very young can be introduced to the unique ways that print and image influence our construction of meaning. The illustrated picture book is an excellent resource with which to begin the process of examining how writing and image offer different narrative possibilities. Children's author-illustrators abound and all use images, color and a full range of artistic features to extend and deepen the meanings conveyed in their written narratives. ${ }^{2}$ It is almost impossible to examine an illustrated picture book and overlook the distinct contribution of words and images. Traditionally, images are used to connote aspects of the narrative that do not appear in the printed text, such as emotions evoked by a particular event. Some authors, such as John Burningham and Maurice Sendak, narrate in a style that sets out an almost parallel text, using the interplay of writing and illustration to transpose different layers and voices in their narratives. It is worth noting that the transposition of narrative structures and voices is an elegant and sophisticated literary device, adopted by authors such as James Joyce, Doris Lessing and, more recently, Sarah Waters and Michael Cunningham, to name only a few. Understanding how this technique is used in the illustrated picture book provides a solid grounding in narrative genres that young children can reinvest throughout their elementary and secondary years. There are also any number of information-based texts written for children that use visual material to supplement explanations and/or factual detail, as well as children's magazines that incorporate images and print to good effect in articles and special features. Arguably, principles of relevance are easier to spot in these kinds of texts than they tend to be in illustrated picture books like Where the Wild Things Are (Sendak, 1963), providing still another important reason for introducing a range of information-based texts in elementary school. In non-fiction produced for children, including 
school textbooks, the inclusion of visual material complements the writing in a manner that tends to facilitate comprehension. Since factual writing tends to be more alien to the young than narrative and, consequently, more difficult to read, let alone read critically, focusing on the complementary role of the visual material in information-based texts becomes central to unlocking their meaning.

The combination of image and print in story is familiar to most children through their own early writing experiences, making opportunities to produce illustrated picture books and a range of information-based texts, such as magazine articles on topics of interest to them, "low tech" points of entry into the world of the multimodal text. The reading-production connection in these instances would involve teachers reading and discussing the conventions and techniques used to make, for example, an illustrated picture book, before asking students to produce one of their own. As the production process moves forward, teachers are certain to discover any number of "teachable moments," from helping their students to use the language of color effectively, to teaching the finer points of characterization and how images and print may be asked to work together to give depth to the depiction of a character.

Products directed at child-consumers, such as cereal boxes, magazine ads and toy packaging, also provide important opportunities to examine the interrelationship of images and writing. These types of products are easy for even the very young to produce for themselves, making them ideally suited to learning first-hand how those who manufacture consumer goods for children design packaging to attract their target audience. Again, the texts to be produced should be examined in detail first, noting the placement of image and print and having students discuss how the composition manages to get their attention, i.e., the overall relevance of words and image in appealing to the child-as-consumer. It is a very short step from reading and producing cereal boxes and magazine ads to examining television commercials directed at children. In the case of commercials, it is important to focus on elements such as speech, color, music and resonant images that attract children's attention and make them want to purchase the item. The Internet is also rife with advertising aimed at children, including Web fan clubs for popular toys such as Barbie ${ }^{\circledR}$. These sites provide teachers with fantastic opportunities to examine how a media text on the Internet works and how advertising is enhanced by phenomena like Web-based fan clubs. ${ }^{3}$ In professional seminars with Quebec teachers, Elementary ELA Resource Team members invited them to explore how toys such as Barbie ${ }^{\circledR}$ or popular action figures could form the basis for children doing their own ethnographic research, an exciting way to introduce questioning techniques and a range of additional research skills to children. 
Another important aspect of examining the Internet has to do with the way it presents information and so-called factual data. It is a common misperception that much of what is conveyed on Web sites is accurate, making instruction that focuses on evaluating what we read and see there vital. In this kind of activity, older children can learn how to evaluate information they retrieve for themselves by comparing Web sites to other more conventional sources of information, such as encyclopedias and resource books in the library. In these, as in the examples above, it is by studying the relevance of images, writing and/or speech, music and other elements that appear on a particular site to the meaning/message conveyed, both as readers and producers, that helps students to "unpack" how these kinds of new media actually work. Secondary students can be invited to also consider the place and prominence of online advertising and what this suggests about the site and/or e-commerce in general.

There are numbers of easy and affordable resources that interweave image, illustration, print and additional features, such as speech, into texts aimed at young adult (i.e., secondary and post-secondary) audiences. As is the case in elementary reading instruction, secondary students should similarly be given opportunities to both read and produce a range of visual texts, since this remains the most effective way to learn about how different systems of representation work. In particular, contemporary media texts provide an excellent opportunity to examine the concept of audience and the techniques that can be used to attract readers' attention, as well as principles of relevance in more sophisticated, conceptually demanding texts. Newspapers, magazines, illustrated picture books, graphic novels, wordless illustrated texts, magazine advertising and television commercials are particularly good resources in this regard and divulge a number of strategies that producers use to establish a relationship with their intended audience. Moreover, excerpts from television or radio newscasts that demonstrate how the same news item can be presented differently, provide opportunities to focus on truth-value and how this is established; for mature students, the contrast may lead to questions about how certain voices, opinions or viewpoints are silenced and to what effect, as well as to questions about ideology and the television production industry in general.

By high school, students are also ready to begin to identify common stylistic and rhetorical techniques, as well as textual structures, codes and conventions that are present in all texts of a particular genre, regardless of the system(s) of representation used, such as would be the case with narrative. Opportunities to compare and contrast traditional and contemporary narratives, for example, provide an important means to examine the different possibilities inherent in films versus novels. As the 
Secondary ELA Resource Team worked with teachers on ways of weaving image and writing into their curriculum, one popular activity became producing book trailers based on, in this instance, a wordless picture book called, The Arrival by Shaun Tan (2007). Book trailers fall into the same genre as movie trailers and abide by most of the same production conventions; however, the invitation to create book trailers also provided an optimum context for examining the construction of a graphic novel and different interpretations of the narrative in greater detail. ${ }^{4}$

\section{Local resources for teachers}

In Quebec, we are also very fortunate to have a number of organizations that provide resources for elementary and secondary teachers who are interested in expanding their pedagogical repertoire to include texts of the new media. One example of a literacy project that combines images and writing is that of the Blue Metropolis Foundation's "Quebec Roots." Initiated in 2005, Quebec Roots is a collaborative effort between authors, photographers, educational resource teachers and K-11 classroom teachers in Quebec that involves students composing ethnographies about their communities in photographs and words. Writers and photographers work as teams, visiting classrooms throughout the production process to provide on-site instruction and feedback on everything from using digital cameras to editing the finished text. The students' anthology is launched at the annual international Blue Metropolis Literary Festival. ${ }^{5}$ Both LEARN-QUEBEC and the Association of Teachers of English of Quebec (ATEQ) also offer a number of different resources and other types of support, including sessions on the media at ATEQ's annual Springboards conference. ${ }^{6}$ In addition, there is no shortage of useful Web sites for teachers and students alike on the different media, as well as free programs, such as Wordle, and these are easy to locate using any of the popular search engines.

\section{Conclusion}

The urgency to embrace non-traditional texts in our educational institutions, whether we teach children, youth, adults or prospective teachers, is critical. There is no question that other issues related to the new media are complex and challenging, but pretending that they are simply the frivolous outcomes of popular culture does a great disservice to our students, who require more than print-based literacy knowledge and skills if they are to fully participate in private and public life in our society and in the world. 


\section{Notes}

1. For more background on the construction of meaning and the integration of visual and conventional communication systems, see Gunther Kress and Theo van Leeuwen (1996), Norman Fairclough (1989), James Gee, Alan Luke, and Cope and Kalantzis (2000).

2. Illustrated picture books are a genre that features illustrations and print. The difference between the genre and books with pictures rests on the fact that the illustrated picture book weaves images into the writing that provide more detail in the story, rather than just literally depicting what has been said in print. Examples of celebrated author-illustrators include John Burningham, Maurice Sendak, Ezra Jack Keats, Molly Bang, Eric Carle, Tomie de Paola, Shirley Hughes and Chris Van Allsburg.

3. The purpose in examining these types of sites should not be to "inoculate" children against presumed negative influences, so much as informing them about how these sites are designed in a conscious and deliberate way. There are many positive aspects to fan clubs such as the one designed for Barbie ${ }^{\circledR}$, including the creation of virtual communities where children can share interests and interact with peers. These positive aspects should be explored, as well as those aspects that focus on consumerism for its own sake.

4. For further information on how to make book trailers, please contact: sela.cycleone@gmail.com.

5. Further information about Quebec Roots and the other educational projects of the Blue Metropolis Foundation are available on the LEARN Web site (http://www.learnquebec.ca) and at http://bluemetropolis.org.

6. The Association of Teachers of English of Quebec (ATEQ) may be contacted through its Web site at http://www.ateq.org. 


\section{References}

Cope, B., \& Kalantzis, M. (2000). Multiliteracies: Literacy learning and the design of social futures. New York: Routledge.

Fairclough, N. (1989). Language and power. New York: Longman.

Giroux, H. (1988). Schooling and the struggle for public life: Critical pedagogy in the modern age. University of Minnesota Press.
Kress, G., \& van Leeuwen, T. (1996). Reading images: The grammar of visual design. New York: Routledge.

Jackson, M. (1982). Thriller [record]. Epic Records. Sendak, M. (1963). Where the wild things are. New York: Harper \& Row.

Tan, S. (2007). The arrival. Arthur A. Levine Books.

Kress, G. (2003). Literacy in the new media age. New York: Routledge.

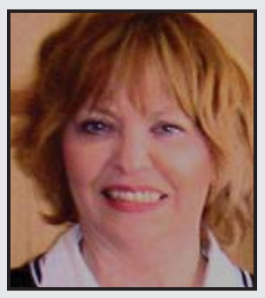

Abigail Anderson is the Coordinator of Curriculum for the teaching of English Language Arts (ELA) at the Quebec Ministry of Education. For the last four years, she has coordinated the work of the ELA Resource Team-exemplary teachers who have visited each school board and schools in the private sector in Quebec to provide ongoing professional development to practicing teachers in elementary and secondary schools. She is an adjunct professor of McGill University's Faculty of Education, and an advocate of critical literacy initiatives and site-based teacher professional development. 